\title{
Revisiting a pilot survey involving contraception and teenage pregnancy in Ayrshire and Arran
}

\begin{abstract}
Susu Salihi, TGP, DFFP, Registrar in Obstetrics and Gynaecology; Denise W Brown, Dip Mgmt, Clinical Effectiveness Facilitator, Elaine Melrose, MBChB, Consultant Obstetrician and Gynaecologist, Sheila Merchant, MBChB, MRCOG, Consultant in Family Planning and Women's Reproductive Health Care, Ayrshire and Arran Acute Hospitals Trust, UK
\end{abstract}

Correspondence: Dr Susu Salihi, Registrar in Obstetrics and Gynaecology, Monklands Hospital, Monkscourt Avenue, Airdrie ML6 OJS. Tel: (44) 1236748748 ext 2901. Email: salihi@doctors.org.uk

(Accepted $16^{\text {th }}$ July 2001)

The Journal of Family Planning and Reproductive Health Care 2002: 28(1): 37-38

\begin{abstract}
Context. How to respond to the challenge of reducing unplanned pregnancy rates in Ayrshire and Arran.

Objectives. (1) To improve understanding of the educational needs of 11-15-year-olds regarding contraception which could be used to inform planning of future sex education in schools in Ayrshire and Arran. (2) To put this in context by reviewing contraceptive usage amongst 14-16-year-old pregnant teenagers.

Design. (1) A questionnaire given to 11-15-year-olds during a sex education class. (2) A retrospective study of pregnant 14-16-year-olds.

Participants. (1) School pupils aged 11-15 from an area of mixed social background $(n=80)$. (2) Pregnant 14-16year-olds presenting at Ayrshire Central Maternity Hospital between September 1997 and March $1998(n=74)$.

Results. (1) Ninety-nine percent of the teenagers said they would use contraception. Seventy-three percent of girls, but only $52 \%$ of boys, were aware of the services available. Ninety percent of girls knew about emergency contraception, but only 59\% of boys. Thirty-three percent thought they received too little sex education at school. Thirty-two percent received no sex education from home, and $10 \%$ 'too little'. More information about sexuallyrelated diseases, safe sex and having a baby was requested. (2) The study of pregnant teenagers showed that $69 \%$ went ahead with their pregnancies, that $71 \%$ were not habitually using contraception and only $4 \%$ were using contraception at the time of conception.

Discussion. Teenagers said they would use contraception. However, boys were not aware of local services giving advice and help to young people, nor about emergency contraception. Teenagers felt they had no or 'too little' sex education at home. They felt too young to become a parent and be 'tied down'.

Conclusions. (1) Teenagers at school want information about a wider range of sexual issues. (2) There is a gap between learning about contraception and its practical use, including emergency contraception. (3) Discussion and reinforcement of sex education at home may not exist for many teenagers. (4) Teenagers at school felt that they were not ready to be parents as this would restrict their social lives and disrupt their education. (5) It is recognised that young men are less well-informed than young women are, and this could impact on safe sex.
\end{abstract}

Introduction

Three recent events led the authors to revisit their 1999 survey, A pilot survey of contraception and teenage pregnancy in Ayrshire and Arran. First, the Department of Health (DOH) consultation paper 'The National Strategy for Sexual Health and HIV'1 intends to 'reduce unwanted pregnancy rates' and 'provide clear information so that people can take informed decisions about preventing STIs, including HIV'. Second, The Healthy Respect Project proposed in "Towards Healthier Scotland" 2 to foster responsible sexual behaviour on the part of Scotland's young people, and third the controversy surrounding emergency contraception obtaining a pharmacy $(\mathrm{P})$ licence.

Ayrshire and Arran had a rate of pregnancies among 13-15-year-olds of 9.78:1000 in 1997-1999, compared to the Scottish rate for 13-15-year-olds of $9.11: 1000^{3}$ for the same period of time.

\section{Method}

A questionnaire was completed in January 1999 by 80 teenagers aged $11-15$ years (63\% girls) during a sex education class, with consent from parents and school authorities. The school had a mixed social background.

A small retrospective supplementary survey was carried out on pregnant 14-16-year-olds presenting at Ayrshire Central Maternity Hospital $(\mathrm{n}=74)$ between September 1997 and March 1998.

\section{Results and discussion \\ School survey}

It was encouraging that $99 \%$ of the teenagers said they would use contraception and knew what basic types were available. Interestingly, $73 \%$ of girls but only $52 \%$ of boys were aware of services giving advice and help to young people, e.g. family planning. Although $90 \%$ of girls seemed to know about emergency contraception, only $59 \%$ of boys were aware. Twenty-two percent of all pupils wished to know more about emergency contraception.

Sex education in schools is presently part of the curriculum and $65 \%$ of teenagers thought that they had sufficient teaching, although $33 \%$ believed that they received too little. Fifty-five percent felt that they had 'enough' sex education at home and 3\% 'too much', but $32 \%$ said that they received 'none' and 10\% 'too little'. Parents may require more information and advice on how to communicate with their children about sexual issues, as discussed by Staniland ${ }^{4}$ in her study of school children.

More information about sexually-related diseases, safe sex and having a baby was requested.

An increasing rate of chlamydial infection amongst the 
population was reported by the Information and Statistics Division (ISD Scotland). ${ }^{5}$ This supports the case for more unambiguous, effective sexual education for young people and their parents, and for the general population.

Most of the teenagers did not feel responsible enough to be parents at their age. This was borne out by comments regarding social and emotional issues such as "only a child myself'; 'my Mum and Dad would kill me'; 'I would still need to go to school'; 'it would tie me down - only an idiot would have a child at 14'. They were also 'frightened' about the possibility of becoming pregnant - 'Terrible. It would be very scary'.

\section{Supplementary survey}

The majority $(\mathrm{n}=58)$ were 16 years old $(78 . \%) ; 17.5 \%$ $(n=13)$ were 15 years old and $5 \%(n=3)$ were 14 years old. The outcomes of the pregnancies showed that $27 \%$ $(\mathrm{n}=20)$ had a termination of pregnancy; $1.3 \%(\mathrm{n}=1)$ had a miscarriage; $2.7 \%(\mathrm{n}=2)$ were unknown outcomes and $69 \%(\mathrm{n}=51)$ had successful deliveries. A high figure continued the pregnancy compared to the latest figures from the Scottish Executive, which showed that $50 \%$ of pregnancies over the similar period of time were terminated. ${ }^{1}$

The contraceptive status of all 74 teenagers prior to conception showed that $4 \%(n=3)$ were using some form of contraception; $70 \%(\mathrm{n}=52)$ were not habitually using contraception; and $26 \%(\mathrm{n}=19)$ stopped using contraception prior to conception. Of the 20 terminations of pregnancy, only one had been using contraception but unfortunately due to diarrhoea this was ineffective, and this strongly suggests that they were unplanned pregnancies. However, information regarding planned or unplanned pregnancies was not available as the study was carried out retrospectively. These figures indicate that there is still a great deal of education required regarding the appropriate use of contraception and emergency contraception, and a more detailed survey would possibly reveal reasons for the lack of contraceptive use.

\section{Conclusions}

As a result of both surveys it was felt that there is still a need to provide teenagers with more effective information about sexual health issues, details regarding contraception (when and how to use it), details about the services available to them, and information about sexually transmitted infections. Breaking down the barriers of open discussion of sexuality in the home would be welcome 'although there are difficulties associated with parent-child communication, especially around sensitive issues' highlighted by HEBS $^{6}$ and would also probably require a major cultural change. The authors felt that these areas required further investigation, discussion and support from all sectors of the community. We were pleased to hear that the school involved in the survey is now a Community School, involved in The Scottish Office 3-year pilot programme which seeks to bring together a team of professionals providing a range of services including education, social work, family support, and health education services. ${ }^{7}$ It is hoped that a follow-up survey will be undertaken at the end of this 3-year pilot programme.

\section{Acknowledgements}

We would like to thank all pupils, teachers, parents, health visitors and education authorities for their co-operation and valuable contribution to this survey.

Statements on funding and competing interests

Funding. None declared.

Competing interests. None declared.

References

Department of Health. National strategy for sexual health and HIV. London: DOH, 2001,

Scottish Office, Health Demonstration Projects. Healthy Respect, Towards a Healthier Scotland - A White Paper on Health. Edinburgh: The Stationery Office, February 1999. ISBN: 010 1426925

Scottish Executive. Clinical outcomes indicators. December 2000, 49-5

Staniland J. Adolescent attitudes to sex education. Br J Sex Med 1996; 23 (3): 18-20 Information and Statistics Division, Genitourinary Medicine Statistics Scotland, year ending 3

March 1999.
HEBS, Parents' role in sex education, Teenage sexuality in Scotland, Briefing Paper, 8. ISBN 1902030168

Executive Education Department. New community schools. Edinburgh, February 2001. News about, issue 3 . 